horticulture. They are paid for land clearance and given loans for inputs. A target of 9,000 acres is to be settled in this way in ten years, with an assessment after five years and an ultimate goal of 2.5 million acres if results of the pilot scheme are positive.

Although enthusiasm ran high for agroforestry, many voiced concern that too much might be expected of it, and were cautious about the prospect of its acceptance as a new discipline. One question raised was whether promotion of agroforestry practices would condemn subsistence farmers to a life of poverty. Dr King, whose agency went into operation only a year ago, answered that "Without inputs (eg fertilisers) they are condemned to a life of misery and mere subsistence. Don't think that if we could get them inputs we would be sitting here. You can grow anything anywhere if you have the money. It is precisely because farmers will remain at this level that some of us believe we could help them in a way that might not be so costly.

"Agroforestry is not the answer to all social problems. But I really think that, given the problems in some of these countries, it ought to be tried."

\title{
Peer seeks to improve UK animal research law
}

LORD Halsbury's Animal Protection Bill successfully passed its first reading in the House of Lords on 16 July. Sometime after the start of the new parliamentary session on 23 October, it will receive its second reading. If it survives that hurdle, it will then be the subject for discussion of a Lords Select Committee before it is given its third reading and eventually handed over to the House of Commons for adoption as law - a procedure which could take up to two years to complete. Earlier this week, the Research Defence Society - which exists to promote the need for research with animals - held a press conference to mark the Bill's first successful reading.

Lord Halsbury, who has been President of the Research Defence Society for twenty years and has been interested in the use of animals in research for much longer, decided to formulate and sponsor the new Bill about one year ago. A series of events had persuaded him that it was time the government "took over its responsibility" to research and opposed the allegations of cruelty to animals in many laboratories being expressed in some of the tabloid newspapers. His Bill is intended to replace the increasingly criticised Cruelty to Animals Act of 1876 as the main piece of UK legislation for ensuring the protection of laboratory animals.

Two events last year convinced Lord Halsbury that the 1876 Act - which, he says is "mostly criticised by those who don't understand it" - needed revising. One was an address to the Annual General Meeting of the RDS in which the speaker expressed his growing distaste at experimenting with animals. ("I realised that I felt that way myself", says Lord Halsbury). The other was last year's Labour Party conference which was attended by a number of slogan bearing anti-vivisectionists and resulted in the Labour government promising to set up a Royal Commission on Animal Protection to look at all aspects of animal rights (a promise which went by default when Labour lost the last election). Setting up a Royal Commission to tackle the problem would have been like "using a sledge hammer to swat a gnat", according to Lord Halsbury. The problems of animals on farms, in slaughter houses, in transit, in laboratories and as pests are all very different. In attempting to cover all five areas, the Royal Commission would be trying to be a "council of perfection".

In spite of his belief that the 1876 Act does work reasonably well, Lord Halsbury has come to the view that there is a need for more restrictive legislation. "Scientists must realise that they cannot live on the 1876 Act forever", he says.

His main criticism of the old Act is that it is too narrow; so his Bill is designed to extend the scope of legislation beyond vertebrates to include other species as and when protection is considered necessary "in the light of advancing scientific knowledge of the nervous systems of such species". Current legislation caters well for "cuddlesome pets". "But the octopus doesn't get protection. This is a highly intelligent creature - at least as intelligent as some of the minor vertebrates." Arthropods, such as crabs, also do not receive protection under the 1876 Act. "Do they have pain nerve endings under their shells?'. The incorporation of new species on to the protected list would, under Lord Halsbury's Bill, be up to the relevant Secretary of State.

The new Bill would also extend the definition of a laboratory and an experiment. "All laboratory usage is included, even a green field". The word experiment has been deliberately excluded from the text of the Bill and replaced by "procedure", which should increase the number of animals entitled to protection. Lord Halsbury expects that the effect of this broadening of scope will be to increase the

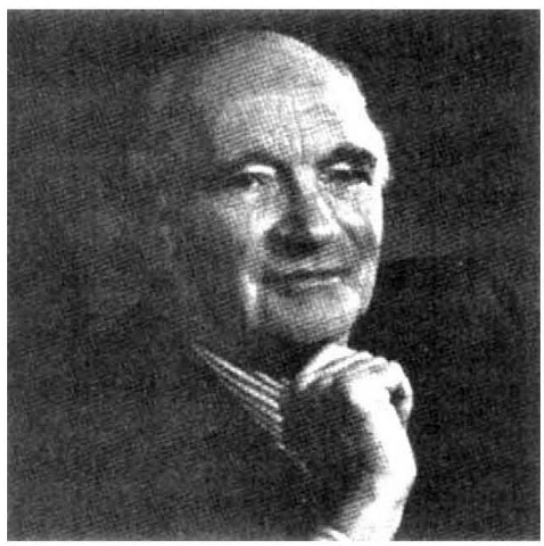

Lord Halsbury: seeks support of scientists number of institutions applying for licences to work with animals.

The overall philosophy behind the Bill is not very different from that behind the 1876 Act. After all "nothing that's said now is any different from what was said then", according to Lord Halsbury who has been studying old Hansards to find out the arguments in vogue before the introduction of the first Act in the 1870s. There are differences in some of the detail, however. For example, the Bill gives power to the Secretary of State to "make regulations to control the procurement, breeding, transport, accommodation, management, veterinary supervision and care of animals for laboratory use". It also gives stronger powers to inspectors, including the right to enter premises licensed under the Bill and to order the killing of any animal thought to be suffering unduly. The Secretary of State would also be required to publish a 'guide to good laboratory practice' which would include advice on the use of alternatives to experiments with animals. The Advisory Committee to the Home Office would be extended to include advising the Secretary of State on novel or controversial procedures and on the incorporation of new species.

For the success of his Bill, Lord Halsbury believes that he must have the support of the scientific community. The Select Committee stage at the House of Lords should provide scientists and others with the opportunity to study the Bill and express their opinions. But the Bill should only be a "little more restrictive" for scientists ("there are very few people who do experiments on octopus"). The antivivisectionists, however, are bound to be critical. "The militants will misrepresent the Bill. They will say that the word 'experiment' was cut out to disguise what scientists are doing, whereas procedure has been used to get animals protected"'.

The UK has amongst the toughest legislation of any country on the protection of laboratory animals and Lord Halsbury believes that it should take a lead in the Council of Europe's deliberations to formulate European guidelines. "The government says let's wait and see what the Europeans do. But the UK should take the lead. I make up my own mind first and other people's later". Judy Redfearn 